\title{
MASTITE GRANULOMATOSA IDIOPÁTICA: ASPECTOS CLÍNICOS, RADIOLÓGICOS E ULTRA-SONOGRÁFICOS*
}

\author{
Cristina Caetano Stefanon ${ }^{1}$, Adriana F. Gonçalves ${ }^{2}$, Roberto Lima ${ }^{3}$, Karin Rossi ${ }^{4}$
}

\begin{abstract}
Resumo 0 objetivo deste estudo é descrever as características clínicas, mamográficas e ultra-sonográficas de três casos de mastite granulomatosa idiopática. Esta afecção pode simular câncer de mama nos exames clínico e mamográfico, porém os achados ultra-sonográficos de múltiplas imagens tubulares hipoecóicas, contíguas e confluentes em mulheres jovens com história de lactação recente sugerem o diagnóstico de mastite granulomatosa idiopática.

Unitermos: Mastite granulomatosa idiopática; Ultra-sonografia; Mamografia.
\end{abstract}

Abstract Idiopathic granulomatous mastitis: clinical, mammography and ultrasound findings.

The aim of this study is to describe the clinical, mammography and ultrasound findings of three cases of idiopathic granulomatous mastitis. This disease can mimic breast carcinoma on clinical and mammographic examinations. However, ultrasound examinations showing multiple clustered and often contiguous tubular hypoechoic lesions in young women with history of recent lactation suggest the diagnosis of idiopathic granulomatous mastitis.

Key words: Idiopathic granulomatous mastitis; Mammography; Ultrasound.

\section{INTRODUÇÃO}

A mastite granulomatosa idiopática (MGI), também denominada mastite lobular granulomatosa, é uma rara doença inflamatória crônica da mama, de etiologia desconhecida. Ocorre principalmente em mulheres jovens e freqüentemente com lactação recente ${ }^{(\mathbf{1})}$. As características clínicas, radiológicas e ultra-sonográficas são semelhantes às do câncer de mama ${ }^{(2-6)}$. $\mathrm{O}$ objetivo deste estudo é descrever as características clínicas, mamográficas e ultrasonográficas de três casos de MGI, bem como a revisão dos casos relevantes publicados na literatura.

\section{RELATO DOS CASOS}

No período de agosto de 2001 a dezembro de 2002, três mulheres tiveram diag-

\footnotetext{
* Trabalho realizado no Centro de Diagnóstico por Imagem (CDI), Vitória, ES.

1. Doutora em Radiologia pela Universidade Federal do Rio de Janeiro (UFRJ), Chefe do Setor de Imaginologia Mamária do Centro de Diagnóstico por Imagem.

2. Médica Radiologista Assistente do Setor de Imaginologia Mamária do Centro de Diagnóstico por Imagem.

3. Mastologista e Oncologista, Chefe do Setor de Oncologia do Hospital Santa Rita de Cássia.

4. Mestre em Ginecologia pela Universidade Estadual de Campinas (Unicamp).

Endereço para correspondência: Dra. Cristina Caetano Stefenon. Rua Saul Navarro, 84, ap. 602, Praia do Canto. Vitória, ES, 29.057-240. E-mail: eventoscdi@hotmail.com

Recebido para publicação em 18/12/2003. Aceito, após revisão, em 10/3/2004.
}

nóstico histopatológico de MGI no Centro de Diagnóstico por Imagem, Vitória, ES. Mamografia e ultra-sonografia foram realizadas nos três casos, bem com a pesquisa de fungos, cultura para tuberculose e bactérias inespecíficas.

\section{Caso 1 (Figuras 1 a 3)}

Paciente de 47 anos de idade, com queixa de nódulo doloroso na mama esquerda, de crescimento rápido. Negava trauma, uso de anticoncepcional oral e história familiar para câncer de mama. Gesta III, o intervalo entre a última gestação e o aparecimento da lesão foi de 24 meses.

O exame clínico revelou área de consistência endurecida, no quadrante superior externo da mama esquerda, associada a eritema e espessamento difuso da pele e complexo aréolo-papilar, indistinguível do carcinoma inflamatório. Não foram observados derrame papilar ou linfadenomegalia axilar clinicamente suspeita.

Mamografia - Aumento difuso da densidade mamária em comparação com a mama contralateral, medindo $8,0 \mathrm{~cm}$, envolvendo três quadrantes da mama, sem microcalcificações ou espículas.

Ultra-sonografia - Múltiplas imagens tubulares hipoecóicas, de ecotextura heterogênea, algumas bem próximas à pele, quase fistulizando.

Biópsia incisional revelou inflamação crônica granulomatosa, com células gigantes, comprometendo lóbulos e estroma, compatível com mastite granulomatosa.
Figura 1. Mama esquerda. Espessamento e hiperemia do revestimento cutâneo, com múltiplas fístulas após a suspensão do corticosteróide.

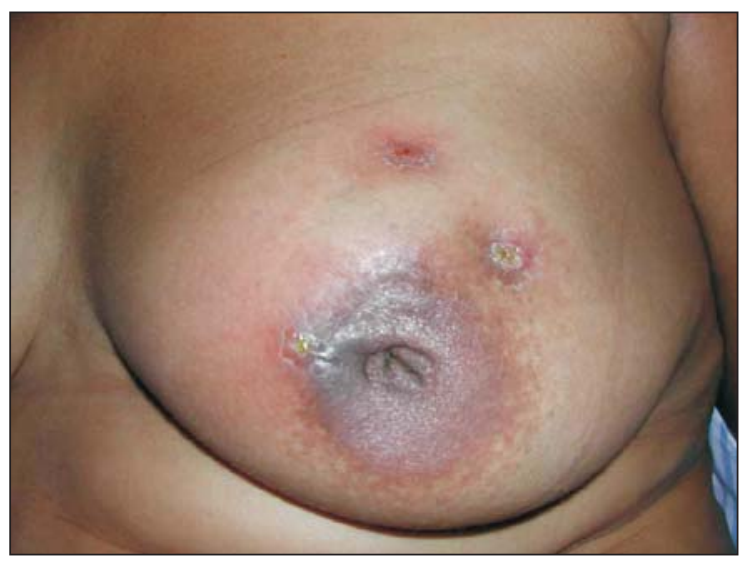




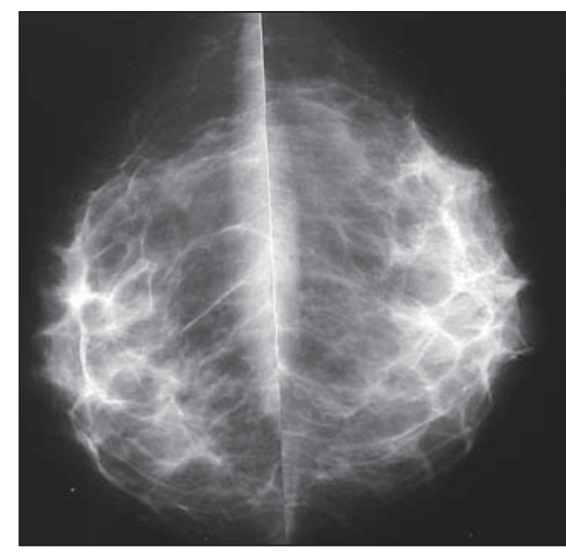

A

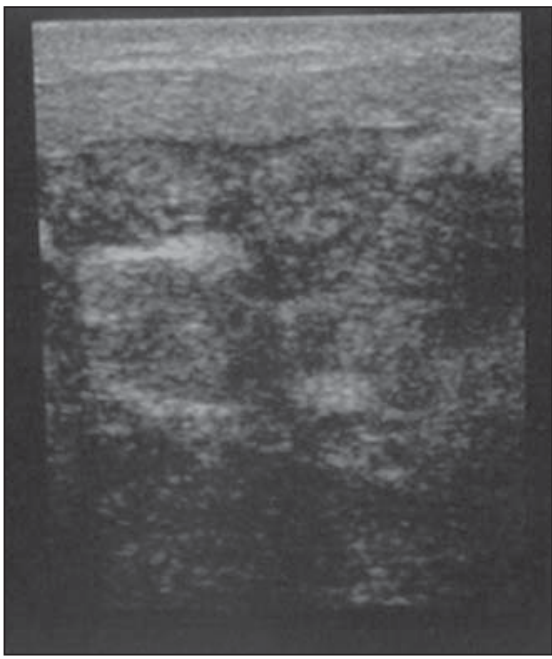

A

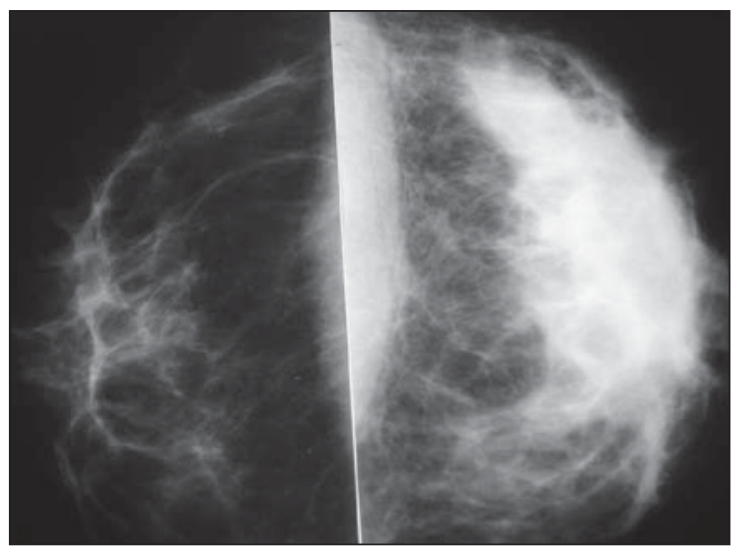

B
Figura 2. Incidências crânio-caudais. Março/2001: mamografia nor mal (A). Julho/2001: aumento difuso da densidade mamária com espessamento cutâneo associado (B).

Figura 3. Ultra-sonografia mama esquerda. Julho/2001: mama de ecotextura heterogênea, com imagens hipoecóicas tubulares, confluentes, com discreto espessamento cutâneo $(\mathbf{A}, \mathbf{B})$. Imagem tubular hipoecóica $\times$ anecóica que se estende em direção à pele, quase fistulizando $(\mathbf{C})$.

Não foi observada neoplasia. A pesquisa de fungos, cultura para tuberculose e bactérias inespecíficas foram negativas. A paciente foi tratada com corticosteróide, com resolução completa do quadro, porém, devido a síndrome de Cushing iatrogênica, o corticosteróide foi suspenso, tendo havido recorrência do quadro com múltiplas fístulas.

\section{Caso 2 (Figuras 4 a 7)}

Paciente de 35 anos de idade, com queixa de nódulo indolor na mama esquerda, de crescimento rápido. Negava trauma, uso de anticoncepcional oral e história familiar para câncer de mama.

Gesta II, o intervalo entre a última gestação e o aparecimento da lesão foi de 18 meses. O exame clínico evidenciou área de consistência endurecida na união dos qua-

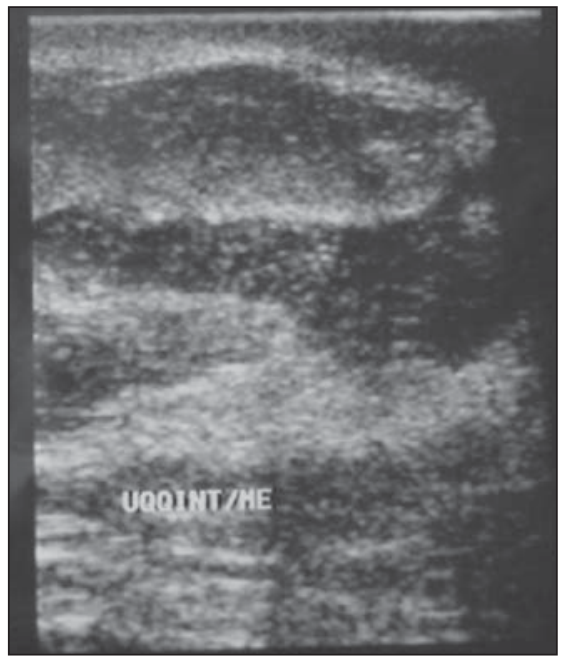

B

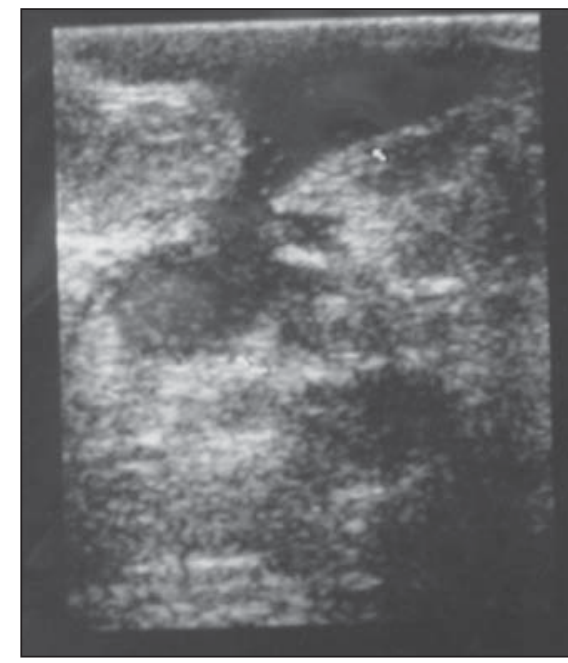

C drantes internos da mama esquerda, com espessamento de pele associado. Não foi observado derrame papilar, eritema cutâneo ou linfadenomegalia axilar clinicamente suspeita.
Mamografia - Presença de densidade focal assimétrica na união dos quadrantes internos, com áreas radiolúcidas de permeio, sem microcalcificações ou espículas, medindo $5,0 \mathrm{~cm}$.

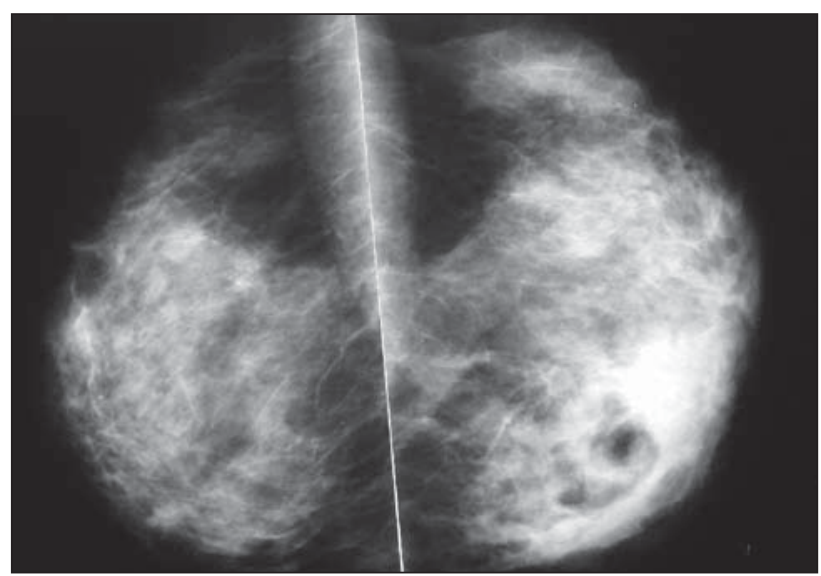

Figura 4. Incidências crânio-caudais. Densidade assimétrica na união dos quadrantes internos da mama esquerda, com áreas radiolúcidas de permeio, sem microcalcificações ou espículas, em correspondência com alteração palpatória. 
Figura 5. Incidência médio-lateral direita. Junho/2002: exame normal (A). Em agosto/2002 referiu nódulo doloroso no quadrante superior externo, periareolar. Mamografia mostrando apenas um linfonodo maior e mais denso que o exame anterior (B).

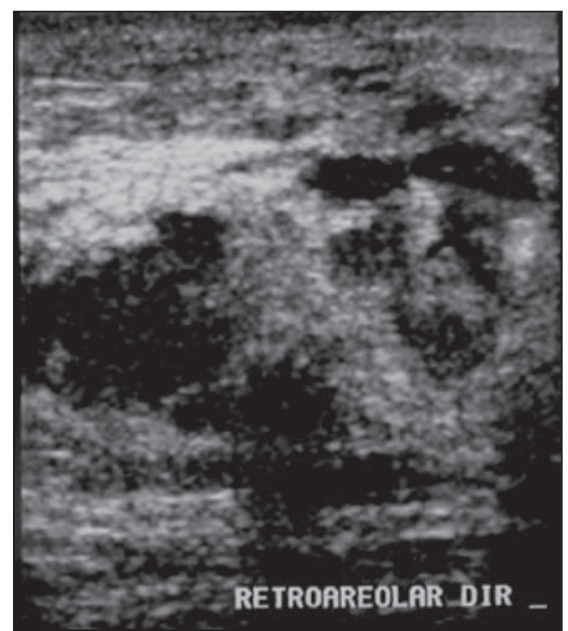

A

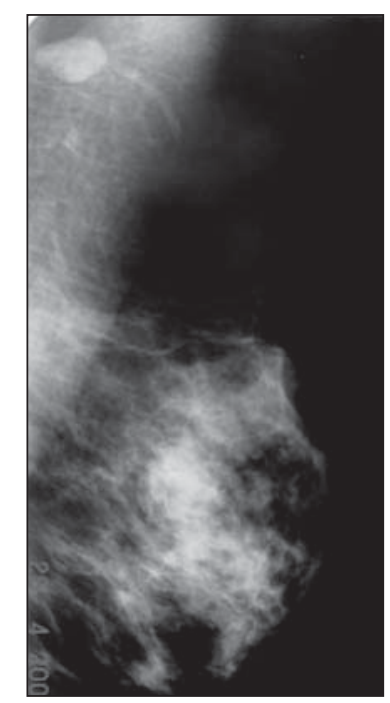

B

Ultra-sonografia - Área hipoecóica irregular, de ecotextura heterogênea, com múltiplas imagens tubulares associadas.

Foi realizada biópsia excisional, que revelou mastite granulomatosa. A pesquisa de fungos, cultura para tuberculose e bactérias inespecíficas foram negativas. A paciente evoluiu sem evidências de doença durante um ano, quando apresentou quadro semelhante na mama contralateral, associado a derrame papilar purulento.

Uma nova mamografia mostrou apenas um linfonodo axilar direito maior e mais denso em relação à mamografia recentemente realizada.

A ultra-sonografia mostrou mama direita de ecotextura bastante heterogênea, com

A

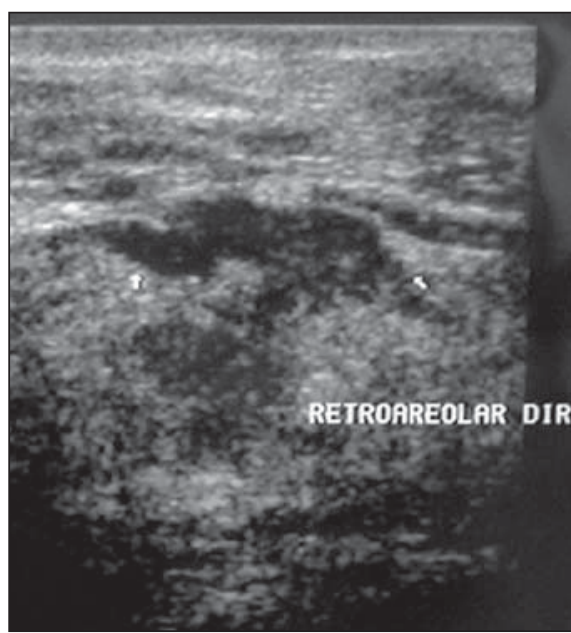

B

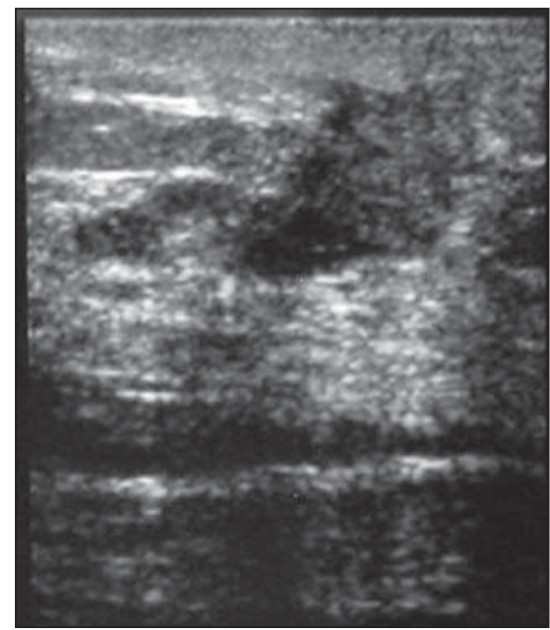

C

Figura 6. Ultra-sonografia, mama direita. Múltiplas imagens tubulares hipoecóicas contíguas, algumas com reforço posterior.

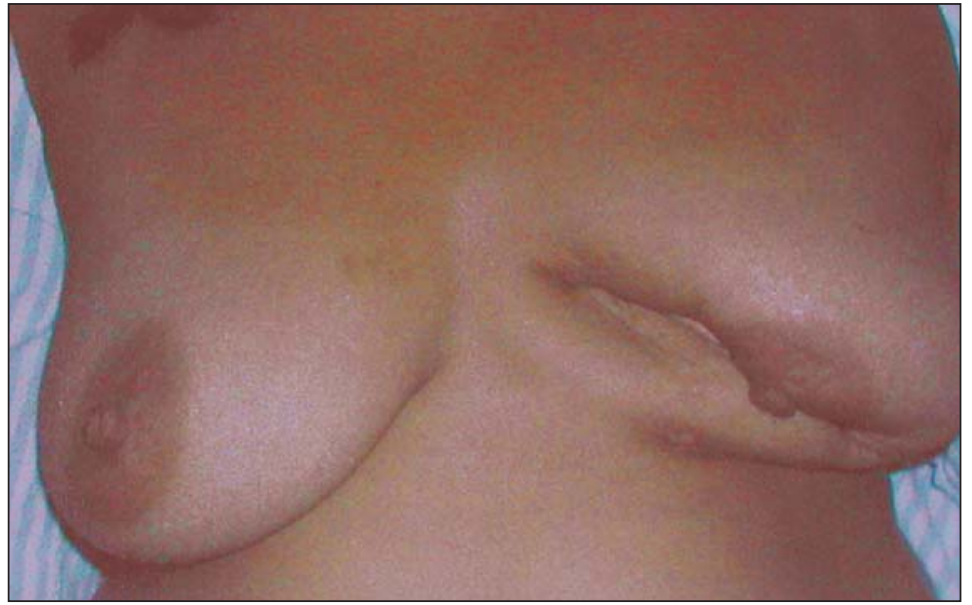

Figura 7. Seis meses após a biópsia excisional. imagens tubulares de permeio, localizadas na região retroareolar e quadrante superior externo, algumas bem próximas à pele.

\section{Caso 3 (Figuras 8 e 9)}

Paciente de 33 anos de idade, com queixa de nódulo doloroso na mama direita. Negava trauma, uso de anticoncepcional oral e história familiar para câncer de mama.

Gesta I, o intervalo entre a última gestação e o aparecimento da lesão foi de 20 meses. O exame clínico evidenciou área de consistência endurecida na união dos quadrantes externos da mama direita, com espessamento de pele associado. Não foram observados derrame papilar ou linfadenomegalia axilar clinicamente suspeita. 


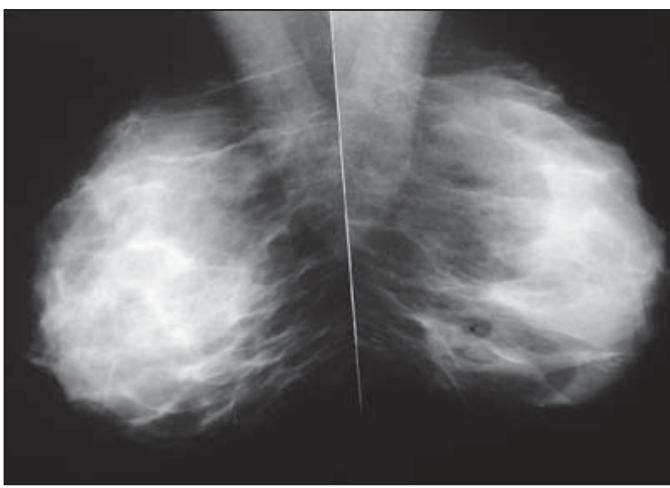

A

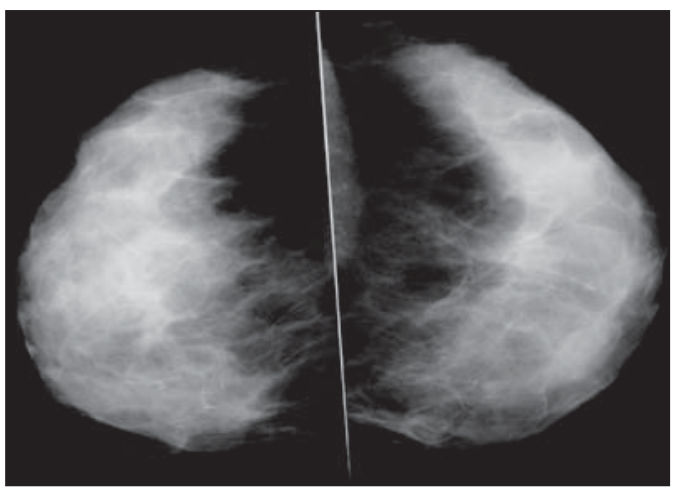

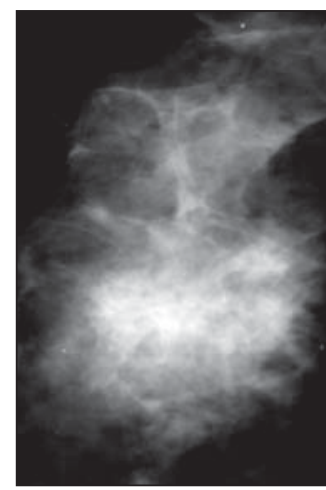

C

Figura 8. Nódulo doloroso na mama direita, de crescimento rápido. Incidências médio-lateral (A) e crânio-caudal. (B): Mamas densas, sem alterações. (C) Incidência crânio-caudal direita um mês após: densidade focal assimétrica na união dos quadrantes externos, com distorção arquitetural e discreto espessamento de pele associados.

Mamografia - Densidade focal assimétrica na união dos quadrantes externos, com áreas radiolúcidas de permeio e distorção arquitetural associada, sem microcalcificações, medindo $6,0 \mathrm{~cm}$. Linfonodos axilares de aspecto habitual.

Ultra-sonografia - Imagens tubulares hipoecóicas tubulares, de ecotextura heterogênea e com espessamento de pele associado.

"Core" biópsia guiada por ultra-sonografia revelou inflamação crônica granulomatosa com células gigantes, comprometendo lóbulos e estroma, compatível com mastite granulomatosa. A pesquisa de fungos, cultura para tuberculose e bactérias inespecíficas foram negativas.

\section{DISCUSSÃO}

Numerosos processos patogênicos responsáveis pela inflamação granulomatosa da mama podem ser incluídos no termo genérico de mastite granulomatosa. Porém, este termo tem sido associado a uma condição clínico-patológica distinta. Em 1972 , Kessler e Wolloch relataram os achados patológicos da mastite granulomatosa que não tinham relação com qualquer infecção específica, trauma ou corpo estranho, e chamaram a atenção para a sua distinção com a mastite de células plasmáticas ${ }^{(\mathbf{1})}$.

A etiologia da MGI é desconhecida. Nenhum microorganismo tem sido isolado e testes histoquímicos para patogênese são rotineiramente negativos. A distribuição perilobular e a característica da inflamação granulomatosa sugerem reação mediada

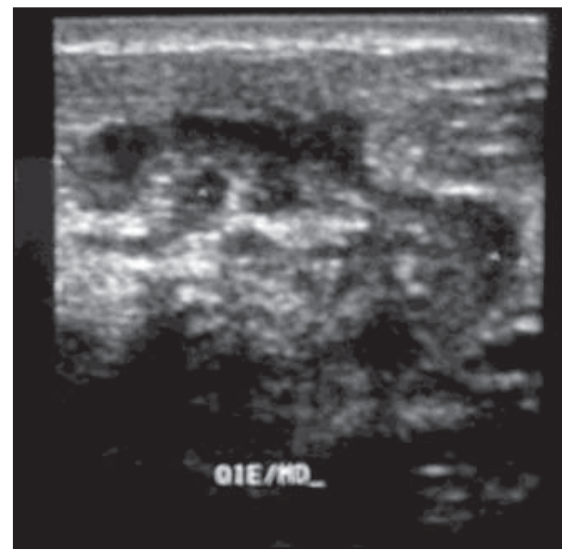

A

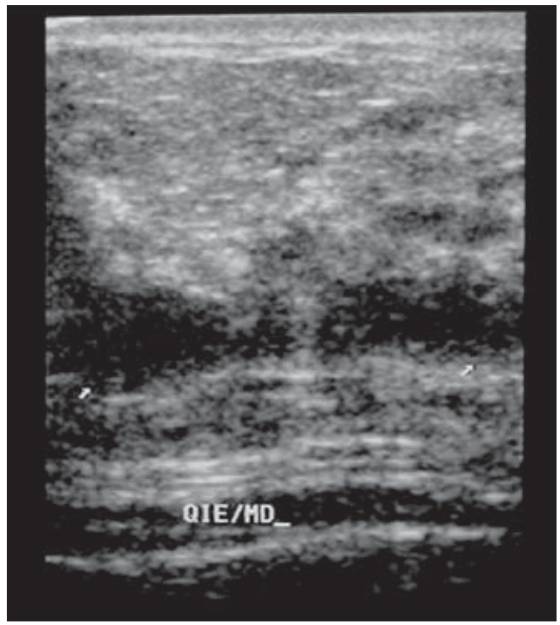

C

Figura 9. Ultra-sonografia, mama direita: múltiplas imagens tubulares hipoecóicas heterogêneas, confluentes e contíguas, com reforço posterior.

por células de uma ou mais substâncias da secreção mamária ou das células lobulares, porém nenhum antígeno específico tem sido identificado. Um fenômeno auto-imune parece improvável, devido à ausência de

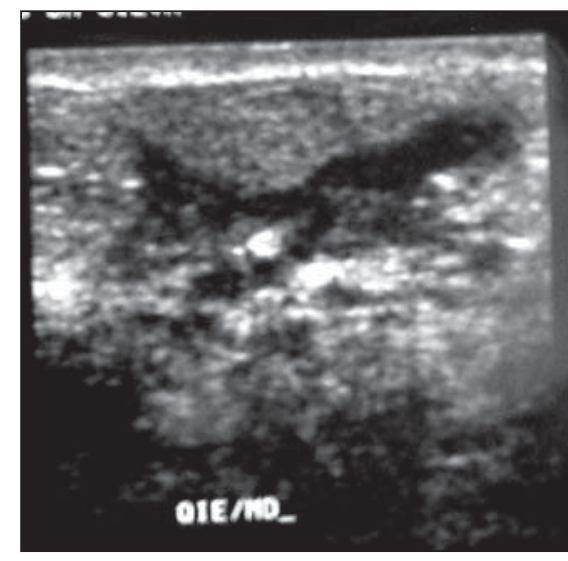

B

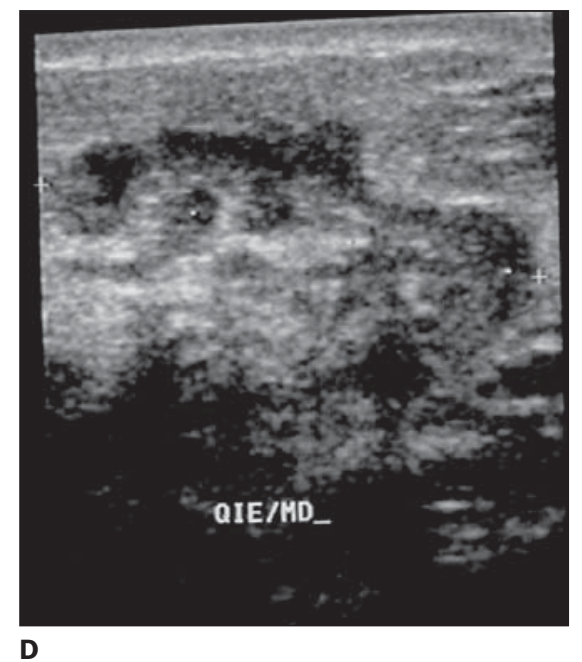

D

vasculite ou de um componente proeminente de células plasmáticas na reação inflamatória $^{(\mathbf{1})}$.

Classicamente, a MGI acomete mulheres jovens, com idade variando entre 17 e 
42 anos (média de 33 anos), e uma forte relação etiopatogênica da MGI com gravidez e lactação tem sido relatada ${ }^{(\mathbf{1 , 3 , 5 , 7 )}}$, pois quase invariavelmente todas as pacientes têm história de gravidez recente, com a MGI usualmente se desenvolvendo nos seis anos após a gestação, embora Going et $a l .{ }^{(7)}$ tenham descrito dois casos 15 anos após o parto. Aguirre-González et al. ${ }^{(2)}$ relataram 16 casos de mastite granulomatosa, sendo um em núlipara, porém estavam incluídos neste relato um caso de tuberculose e dois de mastite de células plasmáticas. Os três casos deste estudo ocorreram em mulheres jovens com história de lactação recente (média de 21 meses).

Alguns autores defendem uma relação entre a MGI e o uso de contraceptivo oral, outros têm relatado aumento na incidência entre mulheres em uso deste medicamento. É sabido que o contraceptivo oral induz hiperplasia dos dúctulos lobulares, causando obstrução por descamação das células epiteliais ductulares, distensão dos dúctulos e, finalmente, reação inflamatória perilobular ${ }^{(\mathbf{1})}$. Deficiência de alfa-1-antitripsina $^{(6)}$, hiperprolactinemia associada com fenotiazina ou metoclopramida também têm sido relatadas em mulheres portadoras de $\mathrm{MGI}^{(\mathbf{1})}$. Não foi observada, nesta série, relação entre o uso de contraceptivo oral ou de qualquer outro medicamento.

Mulheres com MGI tipicamente se apresentam com uma massa endurecida, fixa, não raramente dolorosa, que pode comprometer qualquer área da mama, poupando a região retroareolar, com espessamento cutâneo associado, freqüentemente sugerindo carcinoma. Derrame papilar e linfonodos axilares suspeitos usualmente não estão presentes ${ }^{(\mathbf{1}, \mathbf{3})}$. O envolvimento bilateral é incomum, podendo ocorrer em até $25 \%{ }^{(4,7)}$. Nesta série, os três casos se apresentaram com área de consistência endurecida, poupando a região retroareolar, com espessamento de pele associado, sugestivo de carcinoma, embora linfonodos axilares clinicamente suspeitos não tenham sido detectados.

Há poucos relatos na literatura sobre a aparência mamográfica e ultra-sonográfica da MGI. Os achados mamográficos têm sido descritos como normal, pequenos nódulos mal definidos, densidades assimétricas extensas e distorção do tecido mamá- rio sem microcalcificações ${ }^{(3,8)}$. Em 11 casos descritos por Lee et al. ${ }^{(\mathbf{5})}$, a mamografia mostrou nódulos mal definidos e irregulares $(n=5)$, aumento difuso da densidade $(n=5)$, nódulo ovalado $(n=1)$, espessamento de pele $(n=7)$, distorção do parênquima $(\mathrm{n}=7)$, linfonodos axilares aumentados $(n=6)$ e ausência de calcificações. Na presente série, a mamografia evidenciou densidade focal assimétrica em dois casos e aumento difuso da densidade mamária em um, todos com espessamento de pele associado, sem microcalcificações.

$\mathrm{O}$ aspecto ultra-sonográfico de múltiplas imagens tubulares hipoecóicas e heterogêneas, freqüentemente contíguas e confluentes, foram descritas por Han et al. ${ }^{(3)}$ como fortemente sugestivas de MGI, conforme visto nos três casos deste estudo.

$\mathrm{Na}$ microscopia a MGI se caracteriza por infiltrado inflamatório misto (mononuclear e polimorfonuclear), rico em histiócitos dentro e fora dos lóbulos mamários, formação de granulomas não caseosos e microabscessos (aglomerado de neutrófilos) e ausência de agentes etiológicos infecciosos $^{(\mathbf{1})}$ (Figuras 10 a 14). O diagnóstico de mastite granulomatosa idiopática só

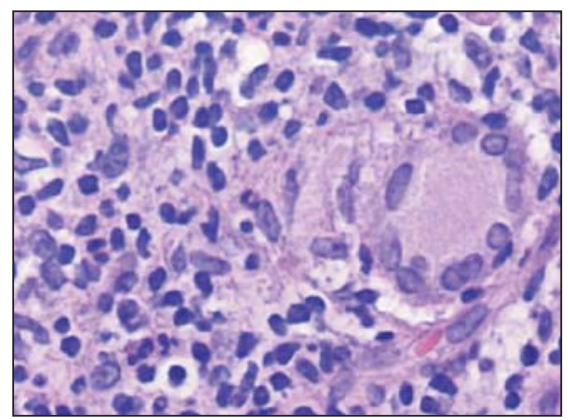

Figura 10. Fotomicrografia - célula gigante multinucleada (hematoxilina-eosina, 400×).

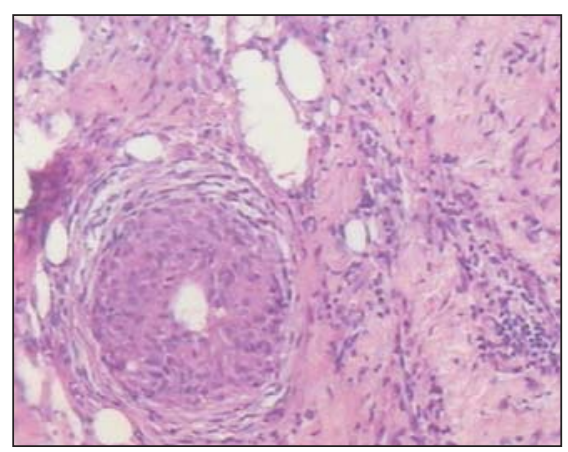

Figura 11. Fotomicrografia - granuloma (hematoxilina-eosina, $100 \times$ ). poderá ser estabelecido após a exclusão de outras causas conhecidas de doenças granulomatosas $^{(\mathbf{1 , 2 , 6 , 8})}$ (Tabela 1).

O tratamento primário recomendado da MGI é a biópsia excisional. Entretanto, em casos de lesões extensas, a cirurgia nem sempre é a melhor opção, devido ao resultado estético extremamente ruim (Figura 4). A persistência, recorrência e o aparecimento de complicações como a formação de abscessos, fístulas (Figura 1) e ulceração de pele não são incomuns e podem ocorrer em até $50 \%$ dos $\operatorname{casos}^{(6,7)}$. A terapia com corticosteróide tem sido eficaz e

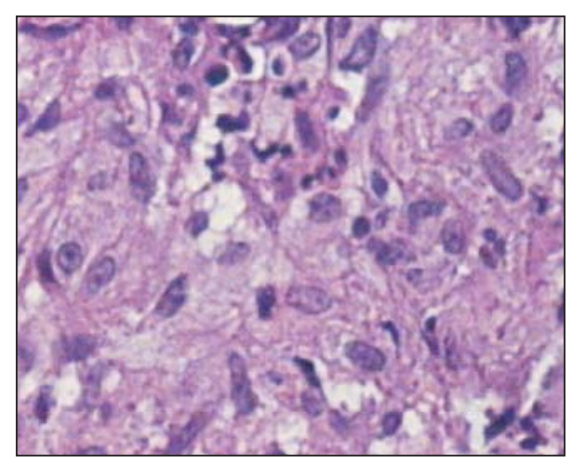

Figura 12. Fotomicrografia - granuloma (hematoxilina-eosina, $400 \times$ ).

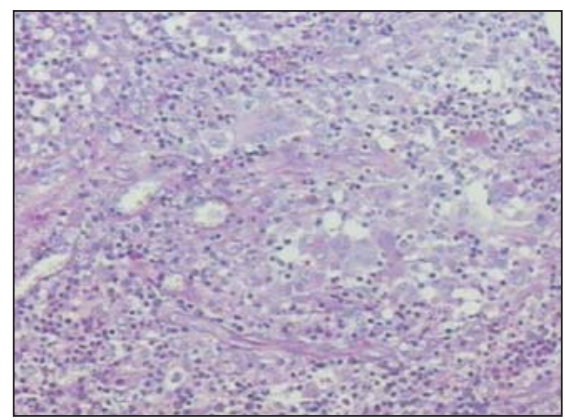

Figura 13. Fotomicrografia - infiltrado misto (PAS $100 \times)$.

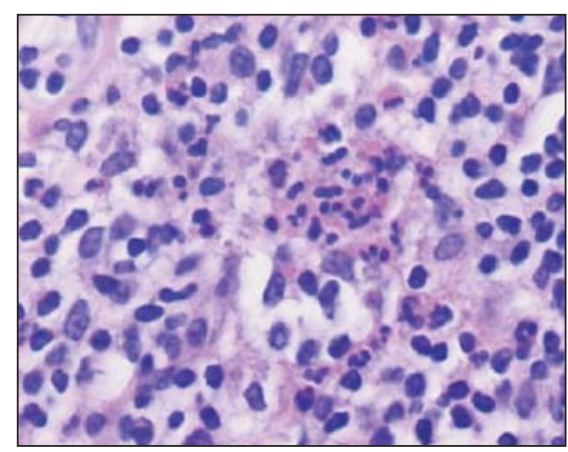

Figura 14. Fotomicrografia - microabscesso (hematoxilina-eosina, $400 \times$ ). 
Tabela 1 Mastite granulomatosa - diagnóstico diferencial.

Infecciosas
Tuberculose, blastomicose, criptococose, his-
toplasmose, actinomicose, filariose, doença
da arranhadura do gato
Processos auto-imunes
Granulomatose de Wegener, arterite de célu-
las gigantes, reação tipo corpo estranho
Diabetes mellitus
Sarcoidose
Idiopática

está indicada para controlar e prevenir a recorrência da doença ${ }^{(\mathbf{1}, 3,7)}$, além de ser uma opção para tratamento primário em lesões extensas.
A MGI pode simular câncer de mama nos exames clínico e mamográfico. Porém, os achados ultra-sonográficos de múltiplas imagens tubulares hipoecóicas, contíguas e confluentes, em mulheres jovens com história de lactação recente, sugere esta rara doença inflamatória crônica da mama.

\section{REFERÊNCIAS}

1. Rosen PP. Breast pathology. Philadelphia: Lippincott-Raven, 1997:32-4.

2. Aguirre-González EH, Verduzco-Rodriguez L, Palet-Guzmán JA. Mastitis granulomatosa. Informe de 16 casos. Ginecol Obstet Mex 1999;67:50911.

3. Han BK, Choe YH, Park JM, et al. Granulomatous mastitis: mammographic and sonographic appearances. AJR 1999;173:317-20.

4. Kumbasar B, Tunaci M, Tunaci A, Balci NC, Tene- keci A, Acunas G. Granulomatous mastitis: mammographic, sonographic, and MR mammographic appearances. Radiological Society of North America. Scientific Exhibits SPACE 0178BR. Chicago; RSNA.2000.

5. Lee J, Oh K, Nam J, Chung S, Kim EK, Kim YJ. Radiologic and clinical features of idiopathic granulomatous lobular mastitis mimicking advanced breast cancer. Radiological Society of North America. Scientific Exhibits SPACE 0158BR. Chicago; RSNA.2000.

6. Schelfout K, Tjalma WA, Cooremans ID, Coeman DC, Colpaert CG, Buytaert PM. Observations of an idiopathic granulomatous mastitis. Eur J Obstet Gynecol Reprod Biol 2001;97:260-2.

7. Going JJ, Anderson TJ, Wilkinson S, Chetty U. Granulomatous lobular mastitis. J Clin Pathol 1987;40:535-40.

8. Osborne BM. Granulomatous mastitis caused by histoplasma and mimicking inflammatory breast carcinoma. Hum Pathol 1989;20:47-52. 